\title{
Ring chromosome 17 syndrome
}

INSERM

\section{Source}

INSERM. (1999). Orphanet: an online rare disease and orphan drug data base. Ring chromosome 17 syndrome. ORPHA:1441

Ring chromosome 17 syndrome is a rare chromosomal anomaly syndrome, resulting from partial deletion of chromosome 17, characterized by hig hly variable manifestations, rang ing from a severe phenotype which presents with lissencephaly and severe intellectual disability to a milder phenotype that includes short stature, microcephaly, intellectual disability, seizures (that may be pharmacoresistant), café-au-lait spots, retinal flecks and minor facial dysmorphism, depending on the presence or absence of the Miller-Dieker critical region. 